Article

\title{
Linking the Determinants of Air Passenger Flows and Aviation Related Carbon Emissions: A European Study
}

\author{
Xuanyu Yue ${ }^{1, *}$ and Julie Byrne ${ }^{1,2}$ \\ 1 UCD Michael Smurfit Graduate Business School, University College Dublin, A94 XF34 Dublin, Ireland; \\ julie.byrne@ucd.ie \\ 2 UCD Energy Institute, University College Dublin, D04 N2E5 Dublin, Ireland \\ * Correspondence: xuanyu.yue@ucdconnect.ie
}

Citation: Yue, X.; Byrne, J. Linking the Determinants of Air Passenger Flows and Aviation Related Carbon Emissions: A European Study. Sustainability 2021, 13, 7574 .

https://doi.org/10.3390/su13147574

Academic Editor: Michael McAleer

Received: 3 June 2021

Accepted: 26 June 2021

Published: 7 July 2021

Publisher's Note: MDPI stays neutral with regard to jurisdictional claims in published maps and institutional affiliations.

Copyright: (c) 2021 by the authors. Licensee MDPI, Basel, Switzerland. This article is an open access article distributed under the terms and conditions of the Creative Commons Attribution (CC BY) license (https:// creativecommons.org/licenses/by/ $4.0 /)$.

\begin{abstract}
Increasing global concern regarding the negative consequences of climate change will see the introduction of comprehensive policy governing aviation-related carbon emissions. With demand for air travel set to accelerate over the next three decades airlines are faced with the task of catering to increased demand while simultaneously achieving emission reductions. In this study we identify the determinants of air passenger flows and flight frequency and assess their impact on carbon emissions and carbon efficiency. Confining our analysis to the European market, we employ Fixed-Effects (FEIV) and Random-Effects (REIV) instrumental variables modelling techniques to 150 intra-Europe routes and find that the factors that are significant in influencing the operational planning decisions of an airline often lead to carbon inefficiencies. Our findings have important implications for both airlines and policymakers. For airlines, we show how the decisions they make to optimise operations can have negative environmental consequences, while we make suggestions as to how policymakers can incentivise airlines to achieve emission reductions.
\end{abstract}

Keywords: environment; aviation; policy; $\mathrm{CO}_{2}$ emissions; flight frequency; passenger flows

\section{Introduction}

The aviation industry has faced a rapidly changing landscape over time and increasing public pressure to mitigate the negative effects of climate change coupled with the anticipated accelerated demand for air travel over the next three decades will lead to further challenges. Consumers increasingly value products and services based on their resource efficiency and in response to changing public sentiment, governments and policymakers are committing to limiting $\mathrm{CO}_{2}$ emissions. As a high-intensity energy user, the transport sector is under scrutiny to adapt the way in which it operates in order to achieve $\mathrm{CO}_{2}$ reductions, particularly relevant to airlines given that passenger air travel produces the highest and fastest growth of individual emissions [1]. Deregulation and the dawn of the Low Cost Carrier (LCC) era has put downward pressure on airfare forcing airlines to operate at increasingly tight margins and, notwithstanding the COVID-19 pandemic, demand for global air transport is anticipated to triple between 2020 and 2050 [2]. Airlines therefore are faced with the seemingly antithetical task of catering to the increased demand for air passenger travel while simultaneously achieving a reduction in aviation-related $\mathrm{CO}_{2}$ emissions. As concerns surrounding the negative impacts of aviation-related $\mathrm{CO}_{2}$ emissions intensify, a significant shift in policy relating to aviation-induced carbon emissions is on the horizon with the introduction of comprehensive policy. Developed by the International Civil Aviation Organization, the Carbon Offsetting and Reduction Scheme for International Aviation (CORSIA) aims to control aviation-related $\mathrm{CO}_{2}$ emissions and will become mandatory for almost all airlines by 2027 [3].

Prior to CORSIA, policy aimed at controlling aviation-related $\mathrm{CO}_{2}$ emissions has been inconsistent in some regions, and completely absent in others. The most notable policy in operation is the EU-Emissions Trading Scheme (ETS), which has included airlines since 
2012 and has been credited by the EU for an aviation sector reduction in the carbon footprint of in excess of 17 million tonnes per annum. However, the EU ETS only applies to flights within the EU and its partners due to opposition from other countries [4], so coverage is far from comprehensive. Evidence into how successful the scheme has been at delivering emissions reductions is mixed with Anger and Köhler [5] and Meleo et al. [6] finding that the scheme is unlikely to achieve significant reductions, while in contrast Seufert et al. [4] find that airlines are more likely to consider their environmental performance if they have to include the direct cost of an ETS. Emission Trading Schemes are not confined to the EU and efforts have been made to establish ETS elsewhere, and there are other countries and regions, for example the US, Australia, and China that have transitorily or continuously implemented ETS that include aviation [4]. However, prior to CORSIA there has been a lack of consistent policy across regions and with over 190 countries included in the scheme [7], CORSIA has a much broader geographical scope than other previous or existing schemes and hence the policy is likely to have a significant impact on airlines.

A large body of literature examines the determinants of air demand and flight frequency, which is crucial for the strategic operational planning of airlines, providing key insights into how to optimally manage changes in passenger flows to maximise the profitability of airlines. A separate strand of literature investigates the environmental consequences of aviation. In this study, we link both by examining the main factors that influence air passenger flows and flight frequency and how the decisions that airlines make to optimise operations may have negative environmental consequences. Airlines will be best placed to develop a framework that satisfies the dual challenge of catering for an increased demand for its services and concurrently reducing $\mathrm{CO}_{2}$ emissions if they can identify the common factors that influence both air passenger flows and carbon emissions. In this study, we do this by first identifying the determinants of air passenger flows and subsequently investigating whether the factors identified are also important determinants of carbon emissions. Confining our analysis to the intra-Europe market where EU-ETS policy is in place, we empirically investigate the factors that are most influential in determining passenger flows and flight frequency. Specifically, we implement both Fixed-Effects and Random-Effects models with instrumental variables to estimate air passenger flows for 150 intra-Europe air routes, and employ clustering analysis to identify differences between the short-haul and medium-haul routes market. We apply simultaneous equations to solve the endogeneity problem between air passenger flows and flight frequency by using an equation-by-equation estimation method and confirm a two-way positive relationship between air passenger flows and flight frequency. We subsequently implement log-linear modelling to investigate whether the most significant determinants of air passenger flows influence aviation-related carbon emissions.

Demand for air travel has increased rapidly over the past thirty years and with that trend set to continue, the resulting sharp increase in carbon emissions has led to extensive efforts to mitigate the effects through technological improvements of aircraft. $\mathrm{CO}_{2}$ is responsible for the majority of the environmental impact from aircraft jet engines [8], and achieving aviation-related emissions reductions has often focused on improved efficiencies through technological advances. Empirical evidence suggests many ways in which airlines can reduce $\mathrm{CO}_{2}$ emissions including improving the energy efficiency of aircraft, employing greener aircraft with advanced technology, retrofitting existing aircraft, and developing alternative jet fuels [3,9-13]. While technology innovations have resulted in a fall in emissions per passenger of over $50 \%$ and improved fuel efficiency over the past decade of approximately $2 \%$ per year, the emissions reductions achieved through efficiency improvements will be insufficient to offset the increased emissions generated by the increase in the volume of air travel [14,15]. Hence, airlines may need to look at demand and operations management to achieve further reductions. Lo et al. [16] point out the lack of econometric evidence of the determinants of aviation-related carbon emissions and state that "emissions interact with such factors as economic performance, political motives, and regulations on market entry" and that these factors "influence the possible outcomes of 
decisions adopted to limit emissions". We account for this in our study by considering both the determinants of aviation-related carbon emissions and other interacting factors.

Demand for flights broadly follows the business cycle and, over the past fifteen years, the aviation industry has experienced fluctuations in passenger traffic as the global economy has moved from prosperity to crisis and subsequent recovery [17]. Many factors have been identified in the literature as contributing to demand uncertainty [17-23]. Uncertain passenger flows are a major challenge for all stakeholders, in particular the airlines themselves, causing difficulties in terms of both planning operational strategies and revenue management activities. Indeed, the airline industry is a difficult environment in which to make investment decisions due to highly cyclical passenger demand [24]. Therefore, it is essential to analyse the influencing factors that affect passenger flows and the supply behaviour of airlines, particularly in light of the fact that forthcoming CORSIA policy will have to be incorporated into the decision making process. A comprehensive analysis of air passenger flows from both the demand and supply sides can provide managerial insight for airlines in how best to respond to market and policy changes, whether in the short-term or the long-term.

\subsection{Demand Side: Air Passenger Flows}

Air passenger flows are affected by many influencing factors, with previous studies demonstrating that air passenger flows are primarily reliant on both geo-economic factors and service-related factors [18]. Geo-economic factors are those factors that are determined by the economic activities and geographical characteristics of the area where air transport service takes places, such as GDP and population $[17,18]$. Service-related factors, on the other hand, are determined by both the quality of service such as the flight frequency, aircraft size, and airfare $[17,18,23]$.

With respect to geo-economic factors, numerous studies find that economic growth has a positive effect on air passenger flows [25-29], while population is another geo-economic factor found to have strong explanatory power $[18,23,30,31]$. The consensus of these studies is that population has a significantly positive influence on air passenger demand, as would be expected as more populated areas will have a higher passenger flows for transport of any type. While the exchange rate between two currencies has also been offered as an influential factor in determining air passenger flows [32-35], we do not include it in our study as most of the routes included in our sample are either domestic flights or routes between two countries that share a common currency, the Euro.

In the literature, flight frequency, airfare, and low-cost carriers entering the market are all service-related factors found to influence demand. Wei and Hansen [36,37] analyse the effects of aircraft size, flight frequency, and seat availability on air passenger flows and find that rising flight frequency can attract more passengers, and Pitfield et al. [20] also find a positive relationship between passenger flows and flight frequency. Airfare is also a key determinant of demand, with airfare and demand found to be negatively related [22,38]. With the advent of low-cost carriers (LCCs) entering the air service market, air travel has become more accessible to passengers, influencing demand [31,39]. Clewlow et al. [31] and Wang et al. [39] find that LCCs stimulate air passenger demand by making the air service market more competitive. As the presence of LCCs on the air transport market becomes more established, lower airfare on a route results, which subsequently promotes the demand for air travel. Boonekamp et al. [38] also document that the presence of LCCs results in a significant increase in demand, particularly on routes that are active with Europe's leading LCCs such as Ryanair and easyJet.

As a result of previous findings in the literature we include the growth rate of GDP per capita and population as the geo-economic factors and flight frequency, airfare, and LCCs as the service-related factors affecting the demand side in our study. 


\subsection{Supply Side: Airlines' Operations}

On the supply side, a strand of literature examines how airlines react to changes in air passenger flows and what factors affect airlines' operational strategies $[17,20,36,37,40,41]$. For example, Wei and Hansen [36] examine the effects of aircraft size, flight frequency, and seat availability on the market share of airlines in the US domestic market and confirm that airlines can achieve greater returns in market share by increasing flight frequency as opposed to increasing aircraft size. Wei and Hansen [37] subsequently show that airlines tend to use the smallest aircraft and increase the flight frequency to adapt to increases in air passenger demand.

Jet fuel price has also been found to be important in influencing the behaviour of airlines, particularly with respect to operational strategies [42]. The effect of the presence of LCCs, particularly for Europe has been widely studied with findings illustrating that the presence of LCCs stimulate demand [38,43-45]. The international development of low-cost airlines is summarised in Francis et al. [43]. Hence, we include jet fuel price, aircraft size, competition, and LCCs as the main influencing factors of an airlines' operations on the supply side.

The remainder of this paper is organised as follows: Section 2 describes the data and variables; Section 3 discusses the empirical models, Section 4 presents the results and discussion, while Section 5 provides concluding remarks.

\section{Data}

Our study is confined to the intra-Europe market and our sample includes fourteen European Union (EU) members (Austria, Belgium, Denmark, Finland, France, Germany, Greece, Ireland, Italy, Netherlands, Portugal, Spain, Sweden, and United Kingdom) and one partner country (Norway). It is worth noting that the United Kingdom left the European Union on 31 January 2020, where in this paper, the data selection is from 2004 to 2019, when the UK was still an EU member. The dataset used in this study includes origin-destination (O-D) passenger traffic data for 150 intra-Europe air transport routes (see more details in Appendix A). Data is collected from the Eurostat database [46], EUROCONTROL [47], OECD [48], Cirium, and U.S. EIA [49]. Monthly data is selected and covers the period from January 2004 to December 2019 inclusive. We intentionally omit the year 2020 from our study due to the impact of the COVID-19 pandemic on aviation. The air traffic information of the 150 routes includes both domestic flights and international flights intra-Europe. All routes are single directional from departure airport to arrival airport, based on air passenger transport between the main airports of each country and their main partner airports. A final sample of 28,800 valid "route-time" observations are extracted from the data collection process. The dataset is a panel dataset, each individual route has its own information for both air passenger flows and airlines' operations, and the economic indicators data for a single route is the country's economic indicator of the origin city. The details of variables and descriptive statistics of variables are separately presented in Tables 1 and 2.

For air passenger traffic between airport-pairs, Barcelona to Madrid is the most frequently trafficked route among the 150 intra-Europe routes in our sample, with approximately 126,161 passengers carried in an average month over our sample period, while Helsinki to Malaga, with only about 9002 passengers carried in an average month, is the least trafficked route. With respect to flight frequency between airport-pairs, Barcelona to Madrid (Helsinki to Malaga) has the highest (lowest) flight frequency among all routes. HICP is a proxy for the country-level rate of inflation of the cost of air transport for passengers, with the UK and Austria having the lowest and highest index values respectively. The use of HICP as a proxy for airfare is potentially problematic, as ideally, route-specific airfare should be used although it is not feasible due to a lack of data availability. We follow the advice of Zhang et al. [23] who similarly use a nationwide index as a proxy for airfare and note that the result should be evaluated with caution. 
Table 1. Details of research variables ${ }^{c}$.

\begin{tabular}{|c|c|c|c|c|}
\hline Variables & Notations & Unit & Data Type & Data Source \\
\hline $\begin{array}{l}\text { Number of departure } \\
\text { passengers }\end{array}$ & $\operatorname{Pax}$ & Person & Monthly & Eurostat \\
\hline $\begin{array}{l}\text { Number of departure } \\
\text { flights }\end{array}$ & Flights & Flight & Monthly & Cirium \\
\hline Average aircraft size & Asize & Seat & Monthly & Cirium \\
\hline GDP per capita ${ }^{a}$ & GDPPC & USD & $\begin{array}{l}\text { Quarterly convert } \\
\text { to monthly }\end{array}$ & OECD \\
\hline $\begin{array}{l}\text { Population of origin } \\
\text { city } b\end{array}$ & Population & Person & Annually & OECD \\
\hline HICP by air transport & HICP & Index $2015=100$ & Monthly & Eurostat \\
\hline $\begin{array}{l}\text { Competition } \\
\text { (Herfindahl-Hirschman } \\
\text { Index) }\end{array}$ & HHI & - & Monthly & $\begin{array}{l}\text { Calculated by authors us- } \\
\text { ing Cirium data }\end{array}$ \\
\hline Number of LCCs & LCCs & - & Monthly & $\begin{array}{l}\text { Calculated by authors us- } \\
\text { ing the Cirium data }\end{array}$ \\
\hline Jet fuel price & Jet fuel & USD per gallon & Monthly & U.S.EIA \\
\hline Distance & Distance & Kilometre & - & Cirium \\
\hline International flights & International & - & Dummy variable & $\begin{array}{l}\text { Calculated by authors us- } \\
\text { ing Cirium data }\end{array}$ \\
\hline $\mathrm{CO}_{2}$ emissions per route & $\mathrm{CO}_{2}$ & Ktonne & Monthly & $\begin{array}{l}\text { Calculated by authors us- } \\
\text { ing Eurostat and EURO- } \\
\text { CONTROL data }\end{array}$ \\
\hline $\begin{array}{l}\text { Total available seat kilo- } \\
\text { metres per route }\end{array}$ & ASK & Seat $*$ Kilometre & Monthly & $\begin{array}{l}\text { Calculated by authors us- } \\
\text { ing Eurostat and Cirium } \\
\text { data }\end{array}$ \\
\hline $\begin{array}{l}\text { Total distance of total } \\
\text { flights per route }\end{array}$ & $\mathrm{KM}$ & Kilometre & Monthly & $\begin{array}{l}\text { Calculated by authors us- } \\
\text { ing Eurostat and Cirium } \\
\text { data }\end{array}$ \\
\hline $\begin{array}{l}\text { EU ETS included avia- } \\
\text { tion }\end{array}$ & ETS & - & Monthly & European Commission \\
\hline
\end{tabular}

Note: ${ }^{b}$ Data for quarterly GDP per capita is adjusted by Industrial production index (IPI); see footnote 3 in [35] ${ }^{a}$ Data for population in 2019 is estimated based on the annual average growth rate of population and data in $2018{ }^{c}$ Definitions of above research variables are displayed in Appendix B.

Table 2. Descriptive information for inputs parameters.

\begin{tabular}{lccccc}
\hline & No. Obs & Mean & SD & Min & Max \\
\hline Pax $_{i t}$ & 28,800 & $36,308.71$ & $19,143.75$ & 506 & 216,976 \\
Flights $_{i t}$ & 28,800 & 322.53 & 166.19 & 23.66 & 2313 \\
Asize $_{i t}$ & 28,800 & 154.60 & 1064.23 & 52.22 & 246.50 \\
GDPPC $_{i t}$ & 28,800 & 2967.27 & $3,384,059.73$ & $1,090,513$ & 6972.40 \\
Population $_{i t}$ & 28,800 & $4,002,756.97$ & 21.35 & 47.00 & $12,981,056.45$ \\
HICP $_{i t}$ & 28,800 & 94.54 & 1636.54 & 1369.78 & 202.78 \\
HHI $_{i t}$ & 28,800 & 4967.81 & 0.68 & 0.93 & 10,000 \\
Jet fuel $_{t}$ & 28,800 & 2.10 & 0.91 & 0.00 & 3.89 \\
LCCs $_{i t}$ & 28,800 & 0.89 & 514.99 & 174 & 5 \\
Distance $_{i}$ & 28,800 & 867.81 & 0.38 & 0 & 3357 \\
International $_{i}$ & 28,800 & 0.82 & $5,776,266.40$ & $375,636.56$ & $56,392,428.52$ \\
CO $_{i t}$ & 18,000 & $8,134,738.68$ & $20,292,250.75$ & $1,729,940$ & $141,772,796$ \\
ASK $_{i t}$ & 18,000 & $38,349,953.12$ & $111,177.81$ & 23,496 & 842,644 \\
MM $_{i t}$ & 18,000 & 234,720 & 0.40 & 0 & 1 \\
ETS $_{t}$ & 18,000 & 0.80 & &
\end{tabular}

While Europe is a relatively small continent, we acknowledge that our results may be influenced by flight distance. While there is no agreement in the literature as to what distance or flight time constitutes a short-haul flight, the general consensus in terms of flight time is a flying time of up to one and a half or two hours. In terms of distance, we adopt the definition set out by Robeco [50] and designate European routes up to $700 \mathrm{~km}$ in distance as short-haul and routes whereas routes over $700 \mathrm{~km}$ are designated as medium-haul. The 150 intra-Europe routes in our sample can be clustered into two groups: 73 shorthaul flights and 77 medium-haul flights. After the clustering procedure, we separately 
estimate both passenger flows and flight frequency equations for the short-haul routes and medium-haul routes.

\section{Methodology}

In order to estimate the demand and flight frequency, we apply Pooled OLS with instrumental variables (Pooled-OLS-IV), Fixed Effects Instrumental Variables (FEIV), and Random Effects Instrumental Variables (REIV) modelling techniques. Linear regression models are widely implemented to estimate air passenger traffic and flights [17-21,23,29]. While several studies exploit the OLS model to analyse air passenger demand $[19,29,38]$, the potential for endogeneity between air passenger flows and flights is of concern. Several solutions have been offered to address this issue including the two commonly selected two-stage least squares (2SLS) and three-stage least-squares (3SLS) approaches $[17,18,20,21,23,29,38]$. Considering the heterogeneity between different air routes, the Fixed-Effects model is more efficient in estimating passenger flows and flights in the presence of the unobserved specific variables $[23,29,51]$, because the Fixed-Effects model takes account of any fixed individual differences between different air routes, such as the distance.

To simultaneously estimate both air passenger flows and flight frequency for the intra-European market using the 2SLS approach to control for endogeneity, a valid set of instruments is required. We consult the literature to identify strong and efficient instruments and find that a wide range of instruments have been proposed. These include cost-shifting instruments such as route distance, Stern-type instruments such as the number of airlines serving a route, instruments denoting non-price characteristics of rival products such as the percentage of rival routes that offer direct flights, and the average distance of rival routes [52-54]. For the demand-side estimation, we use jet fuel prices and the Herfindahl-Hirschman Index (HHI), a measure of how competitive the route is, as our instruments because they directly influence flight frequency but are uncorrelated with air passenger flows. For the supply-side estimation, we select the number of low-cost carriers offering service on a route (LCCs), population and GDP per capita as our instruments because LCCs directly influence aircraft size, while population and GDP per capita directly relate to air passenger flows. In the flight frequency equation estimation, the variable LCCs is one of the instrumental variables used to estimate the average aircraft size in the first stage. The presence of LCCs on routes indirectly affects the number of flights but directly affects the average aircraft size. Givoni and Rietveld [40] estimate that the aircraft size is $14 \%$ higher on routes where low-cost carriers are present. Thus, we use the information that records the presence and absence of LCCs on routes to estimate the endogenous variable in the flight frequency equation. To obtain the data for the time-varying LCC variable, we hand-collect the monthly information for the presence of LCCs on each route from the Cirium database and observe how many LCCs serve each route for each single month.

\subsection{Model Specification for Estimating Air Passenger Flows and Flight Frequency}

We apply a set of instruments to estimate the simultaneous equations of air passenger flows and flight frequency by both the Fixed-Effects (FEIV) and the Random-Effects models (REIV). We also conduct analysis using the Pooled OLS model with instrumental variables (Pooled-OLS-IV) to estimate both equations and to compare with FEIV and REIV models. That is, both air passenger flows and flight frequency equations are separately estimated by using the FEIV, REIV, and Pooled OLS models. The system of equations estimated by the FEIV model is constructed as follows:

$$
\begin{aligned}
\ln \text { Pax }_{i t}= & \alpha_{0}+\beta_{1} \ln \text { Flights }_{i t}+\alpha_{1} \ln \text { HICP }_{i t}+\alpha_{2} \ln \text { Distance }_{i}+\alpha_{3} \text { International }_{i} \\
& +\theta_{1} \ln \text { Population }_{i t}+\theta_{2} \ln \text { GDPPC }_{i t}+\theta_{3} \text { LCC }_{i t}+\eta_{1 i}+\varepsilon_{1 i t} \\
{\text { ln } \text { Flights }_{i t}=}^{=} & \pi_{0}+\beta_{2} \ln \text { Pax }_{i t}+\beta_{3} \ln \text { Asize }_{i t}+\pi_{1} \ln \text { HICP }_{i t}+\pi_{2} \text { International }_{i}+\pi_{3} \text { Distance }_{i} \\
& +\lambda_{1} \ln \text { Jetfuel }_{t}+\lambda_{2} \ln \text { HHI }_{i t}+\eta_{2 i}+\varepsilon_{2 i t}
\end{aligned}
$$


where the subscript $i$ represents the air route and subscript $t$ denotes the month. The error terms $\eta_{1 i}$ and $\eta_{2 i}$ are the unobserved components, which are specific to individual $i$. $\varepsilon_{1 i t}$ and $\varepsilon_{2 i t}$ are the random error terms. For more detailed definitions of dependent and independent variables in Equations (1) and (2), please see Appendix B. Equations (1) and (2) can be rewritten as:

$$
\begin{gathered}
\ln \text { Pax }_{i t}=\beta_{1} \ln \text { Flights }_{i t}+\mathbf{X}_{\mathbf{i t}} \alpha+\mathbf{Z}_{\mathbf{1 i t}} \theta+\eta_{1 i}+\varepsilon_{1 i t} \\
\ln \text { Flights }_{i t}=\beta_{2} \ln \text { Pax }_{i t}+\beta_{3} \ln \text { Asize }_{i t}+\mathbf{X}_{\mathbf{i t}} \pi+\mathbf{Z}_{\mathbf{2 i t}} \lambda+\eta_{2 i}+\varepsilon_{2 i t}
\end{gathered}
$$

where $\mathbf{X}_{\mathbf{i t}}$ is the common exogenous variable in both the passenger flows and flight frequency equations. In addition, $\mathbf{Z}_{\mathbf{1 i t}}=\left(\ln\right.$ Population $\left._{i t}, \ln \mathrm{GDPPC}_{\mathrm{it}}, \mathrm{LCC}_{\mathrm{it}}\right)$ are exogenous variables included in the passenger flows equation but excluded from the flight frequency equation. $\mathbf{Z}_{2 \mathbf{i t}}=\left(\ln\right.$ Jetfuel $\left._{\mathrm{t}}, \ln \mathrm{HHI}_{\mathrm{it}}\right)$ are exogenous variables that determines flights but do not affect air passenger flows.

Without considering the heterogeneity between different routes, error terms $\eta_{1 i}$ and $\eta_{2 i}$ are removed from the Equations (3) and (4), and the system of equations with the REIV and Pooled-OLS model estimation is generated as follows:

$$
\begin{gathered}
\ln \text { Pax }_{i t}=\beta_{1} \ln \text { Flights }_{i t}+\mathbf{X}_{\mathbf{i t}} \alpha+\mathbf{Z}_{\mathbf{1 i t}} \theta+\varepsilon_{1 i t} \\
\ln \text { Flights }_{i t}=\beta_{2} \ln \text { Pax }_{i t}+\beta_{3} \ln \text { Asize }_{i t}+\mathbf{X}_{\mathbf{i t}} \pi+\mathbf{Z}_{\mathbf{2 i t}} \lambda+\varepsilon_{2 i t}
\end{gathered}
$$

where the instrumental variables selection and the definition of variables are the same as in Equations (3) and (4).

In the passenger flows equation, $\ln$ Flights $_{i t}$ is an endogenous variable because air passenger traffic is positively affected by flight frequency at the route level $[17,23]$. In the flight frequency equation, $\ln \operatorname{Pax}_{i t}$ and $\ln A_{s i z} e_{i t}$ are endogenous variables for flight frequency (ibid). According to both theoretical and empirical studies, there is simultaneity among the variables $\ln$ Pax $_{i t}, \ln$ Flights $_{i t}$, and $\ln$ Asize $_{i t}[17,20,21,23]$, a classical issue in the supply-demand interaction. For the air transport market, there is a two-way causation between air passenger demand and flight frequency and aircraft size, particularly between passenger demand and flight frequency [20,21]. More precisely, this two-way causation generates endogeneity between passenger demand and airlines' service supply.

To simultaneously estimate both the air passenger flow (3) and flight frequency (4) equations and control for endogeneity, we select similar instruments to those employed by Mumbower et al. [54] and Zhang et al. [23]. Hence, $Z_{2 i t}$ comprises exogenous variables to determine flights that do not directly affect air passenger flows. Similarly, $Z_{1 i t}$ are exogenous variables that impact air passenger flows but not flight frequency and are used as instruments to estimate the flights equation.

In the FEIV model, the time-invariant variables are removed from Equations (3) and (4). In the first stage, $Z_{2 i t}$ is used as the instrument for estimating the endogenous variable $\ln$ Flights $_{i t}$ in the passenger flows equation. For the flight frequency equation, $Z_{1 i t}$ is the instrumental variable for estimating the endogenous variables $\ln \operatorname{Pax}_{i t}$ and $\ln A s i z e_{i t}$ in the first stage. To verify the validation of the instruments in both equations, we check the validity of the instrument validations through the weak instruments test, Wu-Hausman test for endogeneity, and Sargan overidentifying restrictions. The instruments used in the passenger flow and flight frequency equations have passed these three tests, suggesting our instruments are strong, valid, and good for solving the endogeneity issues among $\ln$ Pax $_{i t}, \ln$ Flights $_{i t}$, and $\ln$ Asize $_{i t}$.

\subsection{Model Specification for Estimating Determinants of Route Carbon Emissions}

For $\mathrm{CO}_{2}$-related analysis, data for $\mathrm{CO}_{2}$ emissions per route is required. However, we could only access data of total passenger traffic $\mathrm{CO}_{2}$ emissions by country from EUROCONTROL since 2010. Due to the above data limits, we estimate route $\mathrm{CO}_{2}$ emissions by applying the following procedure. Firstly, we separately collect the data of the total depar- 
ture flights for air passengers by the reporting country and the number of departure flights by route from Eurostat and calculate the ratio of total departure flights per route to total departure flights by country. We then use this ratio to account for $\mathrm{CO}_{2}$ emissions by each route of the total state $\mathrm{CO}_{2}$ emissions (See Equation (7)). Eventually, 18,000 observations of route $\mathrm{CO}_{2}$ emissions are obtained, covering the period 2010 to 2019.

$$
\text { Route } \mathrm{CO}_{2}=\mathrm{CO}_{2} \text { by country } \times \frac{\text { Total departure flights on a route }}{\text { Total departure flights of the country }}
$$

In order to identify the determinants of $\mathrm{CO}_{2}$ emissions for our sample of European routes, we design two panel data models and estimate using the OLS and Random Effects (RE) estimators. We follow Lo et al. [16] and use the total amount of $\mathrm{CO}_{2}$ emissions and the emission efficiency, given by the amount of $\mathrm{CO}_{2}$ generated per available seat kilometre, as out two dependent variables. Equations (8) and (9) below specify the determinants of $\mathrm{CO}_{2}$ emissions and emission efficiency for European routes.

$$
\begin{aligned}
\ln \mathrm{CO}_{2_{i t}}= & \gamma_{0}+\gamma_{1} \ln \text { Flights }_{i t}+\gamma_{2} \ln \text { Pax }_{i t}+\gamma_{3} \ln \text { Asize }_{i t}+\gamma_{4} \ln \text { HICP }_{i t}+\gamma_{5} \ln \text { Jetfuel }_{t} \\
+ & \gamma_{6} \ln \mathrm{HHI}_{i t}+\gamma_{7} \ln \mathrm{KM}_{i t}+\gamma_{8} \text { ETS }_{t}+\xi_{i t} \\
\ln \mathrm{CO}_{2} \text { ASK }_{i t} & =\gamma_{0}+\gamma_{1} \ln \text { Flights }_{i t}+\gamma_{2} \ln \text { Pax }_{i t}+\gamma_{3} \ln \text { Asize }_{i t}+\gamma_{4} \ln \mathrm{HICP}_{i t}+\gamma_{5} \ln \text { Jetfuel }_{t} \\
& +\gamma_{6} \ln \mathrm{HHI}_{i t}+\gamma_{7} \ln \mathrm{KM}_{i t}+\gamma_{8} \text { ETS }_{t}+\xi_{i t}
\end{aligned}
$$

where the subscript $i$ represents the air route and subscript $t$ denotes the month. In addition, $\gamma_{i}$ represents the coefficients of dependent variables, and $\xi_{i t}$ are error terms.

\section{Results and Discussion}

The results of the panel linear regression models for estimating air passenger flows

\begin{tabular}{|c|c|c|c|c|c|c|}
\hline & \multicolumn{3}{|c|}{ Dependent Variables: $\ln \mathrm{Pax}_{i t}$} & \multicolumn{3}{|c|}{ Dependent Variables: lnFlights ${ }_{i t}$} \\
\hline & (1) & (2) & (3) & (4) & (5) & (6) \\
\hline & Pooled-OLS-IV & FEIV & $R E I V$ & Pooled-OLS-IV & FEIV & $R E I V$ \\
\hline lnFlights $_{i t}$ & $\begin{array}{c}0.568^{* * * *} \\
(0.001)\end{array}$ & $\begin{array}{l}0.568^{* * *} \\
(0.080)\end{array}$ & $\begin{array}{c}0.651^{* * *} \\
(0.067)\end{array}$ & & & \\
\hline $\ln \operatorname{Pax}_{i t}$ & & & & $\begin{array}{c}0.821 * * * \\
(0.001)\end{array}$ & $\begin{array}{c}0.821 * * * \\
(0.074)\end{array}$ & $\begin{array}{c}0.833^{* * *} \\
(0.077)\end{array}$ \\
\hline $\ln$ Asize $_{i t}$ & & & & $\begin{array}{c}-1.369^{* * *} \\
(0.001)\end{array}$ & $\begin{array}{c}-1.369^{* * *} \\
(0.165)\end{array}$ & $\begin{array}{c}-1.086^{* * *} \\
(0.361)\end{array}$ \\
\hline $\operatorname{lnPopulation}_{i t}$ & $\begin{array}{c}0.606^{* * *} \\
(0.002)\end{array}$ & $\begin{array}{c}0.606^{* * *} \\
(0.171)\end{array}$ & $\begin{array}{c}-0.554^{* *} \\
(0.228)\end{array}$ & & & \\
\hline $\operatorname{lnGDPPC}_{i t}$ & $\begin{array}{c}0.572 * * * \\
(0.001)\end{array}$ & $\begin{array}{c}0.572 * * * \\
(0.071)\end{array}$ & $\begin{array}{c}0.228^{* * *} \\
(0.060)\end{array}$ & & & \\
\hline $\mathrm{LCCs}_{i t}$ & $\begin{array}{l}0.047^{* * *} \\
(0.0002)\end{array}$ & $\begin{array}{c}0.047^{* * *} \\
(0.010)\end{array}$ & $\begin{array}{c}0.024^{* * *} \\
(0.007)\end{array}$ & & & \\
\hline $\operatorname{lnHICP} i t$ & $\begin{array}{l}0.242 * * * \\
(0.0003)\end{array}$ & $\begin{array}{c}0.242 * * * \\
(0.034)\end{array}$ & $\begin{array}{l}-0.047 \\
(0.031)\end{array}$ & $\begin{array}{c}-0.157^{* * *} \\
(0.0002)\end{array}$ & $\begin{array}{c}-0.157^{* * *} \\
(0.022)\end{array}$ & $\begin{array}{c}-0.091^{* * *} \\
(0.024)\end{array}$ \\
\hline lnJetfuel $t_{t}$ & & & & $\begin{array}{l}-0.027^{* * *} \\
(0.0001)\end{array}$ & $\begin{array}{c}-0.027^{* * *} \\
(0.007)\end{array}$ & $\begin{array}{c}-0.027^{*} \\
(0.015)\end{array}$ \\
\hline $\operatorname{lnHHI} i t$ & & & & $\begin{array}{c}-0.074^{* * *} \\
(0.0003)\end{array}$ & $\begin{array}{c}-0.074 * \\
(0.042)\end{array}$ & $\begin{array}{c}-0.086^{*} \\
(0.047)\end{array}$ \\
\hline $\operatorname{lnDistance}_{i}$ & $\begin{array}{l}-0.706^{* * *} \\
(0.003)\end{array}$ & & $\begin{array}{c}1.107^{* * *} \\
(0.382)\end{array}$ & $\begin{array}{c}-0.044^{* * *} \\
(0.0002)\end{array}$ & & $\begin{array}{l}-0.065 \\
(0.056)\end{array}$ \\
\hline International $_{i}$ & $\begin{array}{c}0.704^{* * *} \\
(0.003)\end{array}$ & & $\begin{array}{c}-1.018^{* * *} \\
(0.368)\end{array}$ & $\begin{array}{l}0.066^{* * *} \\
(0.0001)\end{array}$ & & $\begin{array}{c}0.053^{* * *} \\
(0.020)\end{array}$ \\
\hline Constant & $\begin{array}{c}-3.653^{* * *} \\
(0.007) \\
\end{array}$ & & $\begin{array}{c}7.253^{* * *} \\
(1.357) \\
\end{array}$ & $\begin{array}{c}5.676^{* * *} \\
(0.004)\end{array}$ & & $\begin{array}{c}4.054^{* * *} \\
(0.940)\end{array}$ \\
\hline Observations & 28,800 & 28,800 & 28,800 & 28,800 & 28,800 & 28,800 \\
\hline Route-specific dummies & Included & Included & Included & Included & Included & Included \\
\hline $\mathrm{R}^{2}$ & 0.910 & 0.598 & 0.935 & 0.939 & 0.619 & 0.953 \\
\hline Adjusted $R^{2}$ & 0.909 & 0.596 & 0.935 & 0.939 & 0.617 & 0.952 \\
\hline Residual Std. Error & $\begin{array}{c}0.160 \\
(\mathrm{df}=28,645)\end{array}$ & & & $\begin{array}{c}0.124 \\
(\mathrm{df}=28,645)\end{array}$ & & \\
\hline F Statistic & & $22,283.510^{* * *}$ & $387,884.600^{* * *}$ & & $15,752.950 * * *$ & $544,135.800^{* * *}$ \\
\hline
\end{tabular}
with three different model specifications: the Pooled OLS model with instruments (PooledOLS-IV), the Fixed-Effects with instruments (FEIV) model, and the Random-Effects with instruments (REIV) model are presented in Table 3 below.

Table 3. Estimations for air passenger flows and flight frequency equations. 
The estimates for air passenger flows are presented in (1), (2), and (3), respectively, and R-squared values of $0.910,0.598$, and 0.935 are observed. We first consider the geo-economic variables included in our analysis: population and GDP per capita. As expected, the coefficient of population is positive and significant at the $1 \%$ level in both the Pooled-OLSIV and FEIV models, suggesting that a larger population size in the origin city generates more passenger flows. The coefficient of GDP per capita is also significantly positive in all models, demonstrating that higher GDP per capita contributes to increased passenger flows $[18,23,29]$. Hence we conclude that population and GDP per capita drive demand for air travel.

According to our results, the service-related variables included in our analysis are also influential in determining passenger flows. Coefficients on flights are significantly positive in all models, indicating that flights and passenger flows are positively related, consistent with previous findings in the literature $[17,20,23,38]$. The latter two models consider the heterogeneity between different air routes so the positive, statistically significant coefficient on the flights variable implies that more flights servicing a route can stimulate air passenger flows. The positive coefficient observed on the LCCs variable in all models indicates that more low-cost carriers engaging in the market have the effect of stimulating demand for air travel, consistent with the literature $[31,38,43,44]$. Finally we look at the airfare proxy, HICP, which captures the price changes of air transport service purchased by passengers and observe a significant and positive coefficient in both the Pooled-OLS-IV and FEIV models. The positive sign of the coefficient in both models is unexpected, as we would expect that higher airfare would lead to lower demand for air service. This unexpected finding is likely due to the use of HICP, a nationwide index, to proxy for airfare, and as Zhang et al. [23] observe, when using such a proxy, the result should be evaluated with caution. While we observe the expected negative sign in the REIV model, the result is insignificant.

We proceed by considering the determinants of flight frequency, the results of which are in (4), (5), and (6). The coefficients of air passenger flows represents the elasticity of flight frequency to passenger traffic, which are $0.821,0.821$, and 0.833 , respectively, in the three models, suggesting that an increase in air passenger flows leads airlines to provide more flights. The average aircraft size has a significantly negative impact on the flight frequency in all three models, supporting findings of previous studies $[17,20,23,38]$. This result is important for the operational strategies of airlines with respect to aircraft choices, the implication being that airlines choose to decrease the aircraft size when they plan to increase the number of flights. A smaller aircraft size allows airlines more flexibility to adjust their operations in response to changes in passenger flows. Like Zhang et al. [23], we find a negative and significant relationship between our airfare proxy and flight frequency in all models. We can offer no explanation as to why this may be the case other than HICP being a weak proxy for airfare and do not have access to route specific data to probe this unexpected finding further.

As expected, the price of jet fuel has a significantly negative effect on flight frequency, indicating that when fuel becomes more expensive, airlines will decrease flight frequency. The Herfindahl-Hirschman Index (HHI) is frequently used to measure the degree of competition in an industry, with high index values indicating lower degrees of competition. When we consider the effect of HHI on flight frequency, the coefficient is negative and significant in all three models. This finding suggests that increased competition on a route leads to an increase in flight frequency. Finally, the coefficient on distance is negative and significant, indicating that the longer the flight distance the lower the flight frequency. We explore our findings further by clustering our sample between short-haul and medium-haul routes and re-estimating our equations, the results of which are presented in Table 4 . 
Table 4. Clustering analysis of route distances.

\begin{tabular}{|c|c|c|c|c|c|c|}
\hline & \multicolumn{6}{|c|}{ Panel A: Air Passenger Flows Equation } \\
\hline & \multicolumn{3}{|c|}{ Short-Haul Routes } & \multicolumn{3}{|c|}{ Medium-Haul Routes } \\
\hline & (1) & (2) & (3) & (4) & (5) & (6) \\
\hline $\ln \operatorname{Pax}_{i t}$ & Pooled-OLS-IV & FEIV & REIV & Pooled-OLS-IV & FEIV & REIV \\
\hline lnFlights $_{i t}$ & $\begin{array}{l}0.461^{* * *} \\
(0.0004)\end{array}$ & $\begin{array}{c}0.461 * * * \\
(0.123)\end{array}$ & $\begin{array}{c}0.534 * * * \\
(0.106)\end{array}$ & $\begin{array}{c}0.634 * * * \\
(0.000)\end{array}$ & $\begin{array}{c}0.634^{* * * *} \\
(0.115)\end{array}$ & $\begin{array}{c}0.697^{* * *} \\
(0.100)\end{array}$ \\
\hline 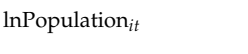 & $\begin{array}{c}0.113^{* * *} \\
(0.001)\end{array}$ & $\begin{array}{c}0.113 \\
(0.235)\end{array}$ & $\begin{array}{c}-0.661 \text { ** } \\
(0.316)\end{array}$ & $\begin{array}{c}1.044^{* * *} \\
(0.000)\end{array}$ & $\begin{array}{c}1.044^{* * *} \\
(0.226)\end{array}$ & $\begin{array}{c}0.037 \\
(0.290)\end{array}$ \\
\hline $\operatorname{lnHICP}{ }_{i t}$ & $\begin{array}{l}0.195^{* * * *} \\
(0.00002)\end{array}$ & $\begin{array}{c}0.195 * * * \\
(0.065)\end{array}$ & $\begin{array}{c}0.014 \\
(0.063)\end{array}$ & $\begin{array}{c}0.266 * * * \\
(0.000)\end{array}$ & $\begin{array}{c}0.266^{* * *} \\
(0.034)\end{array}$ & $\begin{array}{l}-0.023 \\
(0.032)\end{array}$ \\
\hline $\operatorname{lnGDPPC}_{i t}$ & $\begin{array}{l}0.604 * * * \\
(0.0001)\end{array}$ & $\begin{array}{c}0.604^{* * *} \\
(0.108)\end{array}$ & $\begin{array}{c}0.351^{* * *} \\
(0.102)\end{array}$ & $\begin{array}{c}0.580 * * * \\
(0.000)\end{array}$ & $\begin{array}{c}0.580 * * * \\
(0.095)\end{array}$ & $\begin{array}{c}0.264^{* * *} \\
(0.073)\end{array}$ \\
\hline International $_{i}$ & $\begin{array}{c}-0.052 * * * * \\
(0.001)\end{array}$ & & $\begin{array}{c}-1.071 * * \\
(0.453)\end{array}$ & $\begin{array}{c}-0.570^{* * *} \\
(0.000)\end{array}$ & & $\begin{array}{c}0.122 \\
(0.249)\end{array}$ \\
\hline $\operatorname{LCCs}_{i t}$ & $\begin{array}{l}0.045^{* * *} \\
(0.00004)\end{array}$ & $\begin{array}{c}0.045^{* * *} \\
(0.013)\end{array}$ & $\begin{array}{c}0.032 * * * \\
(0.011)\end{array}$ & $\begin{array}{c}0.045^{* * * *} \\
(0.000)\end{array}$ & $\begin{array}{c}0.045^{* * *} \\
(0.012)\end{array}$ & $\begin{array}{c}0.024^{* *} \\
(0.010)\end{array}$ \\
\hline Constant & $\begin{array}{c}0.466^{* * * *} \\
(0.011)\end{array}$ & & $\begin{array}{c}15.430^{* * * *} \\
(5.073)\end{array}$ & $\begin{array}{c}-14.042 * * * \\
(0.000)\end{array}$ & & $\begin{array}{c}3.782 \\
(3.958) \\
\end{array}$ \\
\hline Observations & 14,016 & 14,016 & 14,016 & 14,784 & 14,784 & 14,784 \\
\hline Route-specific dummies & Included & Included & Included & Included & Included & Included \\
\hline $\mathrm{R}^{2}$ & 0.900 & 0.548 & 0.921 & 0.893 & 0.642 & 0.924 \\
\hline Adjusted $R^{2}$ & 0.899 & 0.545 & 0.921 & 0.893 & 0.640 & 0.924 \\
\hline Residual Std. Error & $\begin{array}{c}0.155 \\
(\mathrm{df}=13,938)\end{array}$ & & & $\begin{array}{c}0.164 \\
(\mathrm{df}=14,702)\end{array}$ & & \\
\hline \multirow[t]{4}{*}{ F Statistic } & & $7679.706^{* * *}$ & $152,778.600 * * *$ & & $15,860.370^{* * *}$ & $168,006.800^{* * *}$ \\
\hline & \multicolumn{6}{|c|}{ Panel B: Flight frequency equation } \\
\hline & \multicolumn{3}{|c|}{ Short-Haul routes } & \multicolumn{3}{|c|}{ Medium-Haul routes } \\
\hline & (1) & (2) & (3) & (4) & (5) & (6) \\
\hline lnFlights $_{i t}$ & Pooled-OLS-IV & FEIV & REIV & Pooled-OLS-IV & FEIV & REIV \\
\hline $\operatorname{lnPax}_{i t}$ & $\begin{array}{l}0.764^{* * *} \\
(0.0002)\end{array}$ & $\begin{array}{c}0.764^{* * *} \\
(0.070)\end{array}$ & $\begin{array}{c}0.800 * * * \\
(0.072)\end{array}$ & $\begin{array}{c}0.936^{* * *} \\
(0.000)\end{array}$ & $\begin{array}{c}0.936^{* * *} \\
(0.145)\end{array}$ & $\begin{array}{c}1.116^{* *} \\
(0.456)\end{array}$ \\
\hline $\ln$ Asize $_{i t}$ & $\begin{array}{c}-0.999 * * * \\
(0.0003)\end{array}$ & $\begin{array}{c}-0.999^{* * * *} \\
(0.149)\end{array}$ & $\begin{array}{c}-0.577^{* *} \\
(0.238)\end{array}$ & $\begin{array}{c}-1.774^{* * *} \\
(0.000)\end{array}$ & $\begin{array}{c}-1.774 * * * \\
(0.341)\end{array}$ & $\begin{array}{l}-2.447 \\
(1.501)\end{array}$ \\
\hline $\ln \mathrm{HICP}_{i t}$ & $\begin{array}{c}-0.218 * * * \\
(0.00004)\end{array}$ & $\begin{array}{c}-0.218^{* * * *} \\
(0.024)\end{array}$ & $\begin{array}{c}-0.157^{* * *} \\
(0.033)\end{array}$ & $\begin{array}{c}-0.140 \text { *** } \\
(0.000)\end{array}$ & $\begin{array}{c}-0.140^{* * *} \\
(0.048)\end{array}$ & $\begin{array}{l}-0.138 \\
(0.099)\end{array}$ \\
\hline lnJetfuel $t_{t}$ & $\begin{array}{c}-0.008^{* * * *} \\
(0.00003)\end{array}$ & $\begin{array}{l}-0.008 \\
(0.008)\end{array}$ & $\begin{array}{l}-0.009 \\
(0.014)\end{array}$ & $\begin{array}{c}-0.055^{* * *} \\
(0.000)\end{array}$ & $\begin{array}{c}-0.055^{* * *} \\
(0.018)\end{array}$ & $\begin{array}{l}-0.075 \\
(0.060)\end{array}$ \\
\hline $\operatorname{lnHHI}{ }_{i t}$ & $\begin{array}{c}-0.107^{* * * *} \\
(0.00004)\end{array}$ & $\begin{array}{c}-0.107^{* * *} \\
(0.036)\end{array}$ & $\begin{array}{c}-0.136^{* * *} \\
(0.038)\end{array}$ & $\begin{array}{c}-0.031^{* * *} \\
(0.000)\end{array}$ & $\begin{array}{l}-0.031 \\
(0.077)\end{array}$ & $\begin{array}{c}0.082 \\
(0.238)\end{array}$ \\
\hline International $_{i}$ & $\begin{array}{l}0.084 * * * \\
(0.00001)\end{array}$ & & $\begin{array}{c}0.067^{* * *} \\
(0.021)\end{array}$ & $\begin{array}{c}-0.022 * * * \\
(0.000)\end{array}$ & & $\begin{array}{c}0.091 \\
(0.270)\end{array}$ \\
\hline Constant & $\begin{array}{c}4.671^{* * * *} \\
(0.001)\end{array}$ & & $\begin{array}{c}2.143^{* * * *} \\
(0.796) \\
\end{array}$ & $\begin{array}{c}5.861^{* * * *} \\
(0.000)\end{array}$ & & $\begin{array}{c}6.387^{* * * *} \\
(2.051) \\
\end{array}$ \\
\hline Observations & 14,016 & 14,016 & 14,016 & 14,784 & 14,784 & 14,784 \\
\hline Route-specific dummies & Included & Included & Included & Included & Included & Included \\
\hline $\mathrm{R}^{2}$ & 0.925 & 0.667 & 0.933 & 0.901 & 0.586 & 0.876 \\
\hline Adjusted $R^{2}$ & 0.924 & 0.665 & 0.933 & 0.901 & 0.584 & 0.875 \\
\hline Residual Std. Error & $\begin{array}{c}0.112 \\
(\mathrm{df}=13,938)\end{array}$ & & & $\begin{array}{c}0.142 \\
(\mathrm{df}=14,702)\end{array}$ & & \\
\hline F Statistic & & $10,393.920 * * *$ & $176,237.200^{* * *}$ & & $6486.890^{* * *}$ & $93,498.880 * * *$ \\
\hline
\end{tabular}

Note: ${ }^{* *} p<0.05 ;{ }^{* * *} p<0.01$; the robust standard errors are displayed below the coefficients.

In panel $\mathrm{A}$, the results of the air passenger flows are displayed. Again, the findings suggest that the number of flights, GDP per capita, population, and LCCs are positively related to air passenger flows. While the size of the coefficient on flights, GDP per capita, and LCCs is similar for both short-haul and medium-haul routes, the size of the coefficient on population is much larger for medium-haul routes than on short-haul routes. This may be because airports and airlines serving cities with smaller populations do not operate as many longer distance flights, and passengers from smaller cities connect via the larger cities for longer flights.

The results of the flight frequency estimation are presented in panel B. The coefficients are all of the same sign observed in the first estimation, but when the sample is separated between short-haul and medium-haul flights, clear differences emerge. The coefficient on aircraft size is much larger for medium-haul routes than short-haul routes. While it is clear that flight frequency and aircraft choice are influential with respect to the operating effectiveness of airlines, our results demonstrate a stronger relationship between these two variables for longer flights. One explanation for this may be the difference in the crew costs because pilots and crew operating larger aircraft are paid more than those operating smaller aircraft. By catering for changes in demand on longer routes by adjusting flight frequency and reducing aircraft size, the savings to the airline are greater. When we consider the price of jet fuel, we again find that the effect is larger on medium-haul routes. The cost of fuel 
greatly affects the profitability of airlines, and it is easy for airlines to adjust flight frequency in response and as longer flights consume more jet fuel, reducing flight frequency on longer routes will lead to greater savings.

Our results so far show that the important influential factors for determining air passenger flows are flights, population, GDP per capita, and LCCs, while the important influential factors for determining flight frequency are aircraft size, the price of jet fuel, competition, and distance. We next consider how these results influence carbon emissions. Airline operations are complex and require the balancing of conflicting objectives to operate at profit-maximising levels and, to cater for growing demand, airlines can choose to increase flight frequency or to increase aircraft size. There appear to be higher returns to flight frequency in terms of operating effectiveness, with the main reasoning for increasing flight frequency being that it reduces passengers' schedule delay. Therefore, the optimal strategy for airlines seems to be to increase flight frequency and reduce aircraft size to accommodate changes in passenger flows. We now explore whether this strategy will have negative environmental consequences by examining whether the factors that influence flight frequency at the route level also influence the level of $\mathrm{CO}_{2}$ emissions. In our analysis, we consider total $\mathrm{CO}_{2}$ emissions on each route and $\mathrm{CO}_{2}$ emissions per available seat kilometre, which is a measure of emission efficiency, on each route. The results are presented in Table 5 and show that most of the explanatory variables are statistically significant in determining both total carbon emissions and emission efficiency.

Table 5. Regression results for $\mathrm{CO}_{2}$ emissions at the route level.

\begin{tabular}{|c|c|c|c|c|}
\hline & \multicolumn{2}{|c|}{ Dependent Variables: $\ln \mathrm{CO}_{2 i t}$} & \multicolumn{2}{|c|}{ Dependent Variables: $\ln \mathrm{CO}_{2} \mathrm{ASK}_{i t}$} \\
\hline & (1) & (2) & (3) & (4) \\
\hline & Pooled-OLS & $R E$ & Pooled-OLS & $R E$ \\
\hline \multirow{2}{*}{ lnFlights $_{i t}$} & $0.108^{* * *}$ & $0.172 * * *$ & $0.108^{* * *}$ & $0.172 * * *$ \\
\hline & $(0.024)$ & $(0.021)$ & $(0.024)$ & $(0.021)$ \\
\hline \multirow[t]{2}{*}{$\ln \operatorname{Pax}_{i t}$} & $0.134^{* * *}$ & $0.048^{* *}$ & $0.134^{* * *}$ & $0.048^{* *}$ \\
\hline & $(0.023)$ & $(0.023)$ & $(0.023)$ & $(0.023)$ \\
\hline \multirow[t]{2}{*}{$\ln$ Asize $_{i t}$} & 0.078 * & 0.022 & $-0.922^{* * *}$ & $-0.978^{* * *}$ \\
\hline & $(0.046)$ & $(0.040)$ & $(0.046)$ & $(0.040)$ \\
\hline \multirow[t]{2}{*}{$\ln \mathrm{HICP}_{i t}$} & $0.036^{* * *}$ & $-0.072^{* * *}$ & $0.036^{* * *}$ & $-0.072^{* * *}$ \\
\hline & $(0.012)$ & $(0.017)$ & $(0.012)$ & (0.017) \\
\hline \multirow[t]{2}{*}{ lnJetfuel $_{t}$} & $-0.038^{* * *}$ & $-0.054^{* * *}$ & $-0.038^{* * *}$ & $-0.054^{* * *}$ \\
\hline & $(0.006)$ & $(0.016)$ & $(0.006)$ & $(0.016)$ \\
\hline \multirow[t]{2}{*}{$\ln \mathrm{HHI}_{i t}$} & 0.025 & 0.030 * & 0.025 & 0.030 * \\
\hline & $(0.021)$ & $(0.018)$ & $(0.021)$ & $(0.018)$ \\
\hline \multirow[t]{2}{*}{$\ln \mathrm{KM}_{i t}$} & $0.781 * * *$ & $0.772 * * *$ & $-0.219^{* * *}$ & $-0.228 * * *$ \\
\hline & $(0.010)$ & $(0.009)$ & $(0.010)$ & $(0.009)$ \\
\hline \multirow[t]{2}{*}{$\mathrm{ETS}_{t}$} & $0.016^{* * *}$ & $0.043^{* * *}$ & $0.016^{* * *}$ & $0.043^{* * *}$ \\
\hline & $(0.005)$ & $(0.014)$ & $(0.005)$ & $(0.014)$ \\
\hline \multirow[t]{2}{*}{ Constant } & $3.168 * * *$ & $4.560 * * *$ & $10.076^{* * *}$ & $11.468^{* * *}$ \\
\hline & $(0.408)$ & $(0.456)$ & $(0.408)$ & $(0.456)$ \\
\hline Observations & 18,000 & 18,000 & 18,000 & 18,000 \\
\hline Route-specific dummies & Included & Included & Included & Included \\
\hline $\mathrm{R}^{2}$ & 0.982 & 0.985 & 0.988 & 0.990 \\
\hline Adjusted $\mathrm{R}^{2}$ & 0.982 & 0.985 & 0.988 & 0.990 \\
\hline F Statistic $(\mathrm{df}=156 ; 17,843)$ & $6388.768^{* * *}$ & $1,178,921.000^{* * *}$ & $9285.141^{* * *}$ & $1,746,014.000 * * *$ \\
\hline
\end{tabular}

The results show that the number of passengers and number of flights are positively associated with $\mathrm{CO}_{2}$ emissions, suggesting that more passengers and more flights lead to greater total $\mathrm{CO}_{2}$ emissions and greater carbon inefficiencies. The contribution to carbon inefficiencies may be because increased air traffic leads to increased congestion, both on the ground and in the air, the latter of which may lead to sub-optimal flight paths. Consistent with Lo et al. [16], we find that route distance increases total $\mathrm{CO}_{2}$ emissions but decreases $\mathrm{CO}_{2}$ emissions per available seat kilometre. The greater emissions efficiency observed in relation to distance is likely due to a combination of factors such as the take-off phase being more carbon-intensive than the cruising segment of the flight and the tendency to utilise 
less fuel-efficient aircraft on regional and shorter flights [55]. We further find that aircraft size and $\mathrm{CO}_{2}$ emissions per available seat kilometre are negatively related, indicating that larger aircraft generate lower $\mathrm{CO}_{2}$ per ASK [16]. The coefficient on the price of jet fuel is negative and significant in all regressions, indicating that higher fuel prices lead to lower emissions. This result is as we would expect but is in contrast to the findings of Lo et al. [16] who, in a study confined to four regional Italian airports, find that fuel price is a positive determinant of total $\mathrm{CO}_{2}$ emissions.

Our results have important implications for airlines. We identified the main determinants of passenger demand and flight frequency. In response to increases in air passenger demand, we find that firms tend to favour increasing flight frequency while reducing aircraft size. However, this choice with regards to flight frequency and aircraft size have negative environmental consequences, supporting the observation that "large aircraft have lower environmental per passenger km costs" [56]. If airlines wish to reduce emissions, they could amend the way in which they cater for changes in passenger flows by increasing aircraft size (increasing carbon efficiency) as opposed to increasing flight frequency (decreasing carbon efficiency).

\section{Concluding Remarks}

In this study, we examine the main factors that influence air passenger flows and flight frequency and how the decisions airlines make to optimise operations may have negative environmental consequences. Confining our analysis to the European market, we identify the determinants of air passenger flows and flight frequency on 150 intra-Europe air routes by applying Fixed-Effects and Random-Effects models with instrumental variables, and employ clustering analysis to identify differences between the markets short-haul and medium-haul routes. We subsequently implement log-linear modelling to investigate whether the most significant determinants of air passenger flows influence aviation-related carbon emissions. Our results demonstrate that the significant factors that influence the operational planning decisions of an airline often lead to carbon inefficiencies. For example, we find that while reducing aircraft size may increase operational efficiency, it is a driver of carbon inefficiency.

Our findings give insights into the challenges that airlines will face with the introduction of CORSIA as we demonstrate that the pursuit of current strategies to adapt to changes in passenger flows lead to an increase in carbon emissions and considerable inefficiencies. While aircraft have become greener and more efficient in recent years, these efficiency gains will be outstripped by the increase in demand for air travel. As a result, achieving the level of $\mathrm{CO}_{2}$ emissions mandated by CORSIA cannot be achieved by airlines relying on efficiency improvements alone. To avoid large-scale policy costs, we suggest ways in which airlines can adjust their response to changes in passenger demand that have lower environmental consequences.

While global policy on aviation emissions has been inconsistent to date, the implementation of CORSIA from 2021 seeks to comprehensively combat the negative environmental consequences of airlines, and our findings have numerous implications for policymakers. First, the forthcoming CORSIA is largely silent with respect to aircraft size, and we find, consistent with Lo et al. [16], that aircraft size can reduce $\mathrm{CO}_{2}$ emissions and improve $\mathrm{CO}_{2}$ efficiency. Therefore, providing incentives to airlines to cater for increases in demand by increasing aircraft size should have positive environmental consequences. Also, our finding that carbon inefficiencies are more of a concern on shorter routes can also inform policy. Shorter routes tend to be served by older, less efficient aircraft, so incentives to retrofit these fleets is an option to policymakers. We find that airlines respond to the increasing price of jet fuel by reducing flight frequency, and the price of jet fuel is a negative determinant of $\mathrm{CO}_{2}$ emissions on a route. Hence, policymakers can incentivise airlines to seek alternatives to jet fuel by taxing jet fuel at a higher rate to achieve emission reductions.

Our analysis has some shortcomings, mainly related to data availability. First, due to the lack of available data regarding route-specific airfare, we follow previous scholars and 
use a nationwide proxy. While airfare is an important determinant of both demand for air travel and flight frequency, we find our proxy necessitates that any results obtained in our analysis regarding its importance should be evaluated cautiously, and hence, this study remains reticent as to the impact of airfare. Second, our analysis focuses on passenger transport and ignores the environmental consequences of cargo transport. However, as air passenger travel emits four times the amount of $\mathrm{CO}_{2}$ as freight, we are confident in the robustness of our results.

Comprehensive policy to govern aviation related emissions will lead to difficulties for airlines who will need to develop a framework that maximises operations allowing them to cater for increases in demand while also ensuring policy compliance. We identify the most influential factors that determine demand and flight frequency at the route level, and which of these factors also contribute to carbon (in)efficiencies. While our research is informative for airlines as to how the decisions they make to optimise operations can negatively impact the environment, airlines are not homogeneous. Hence, future research could focus on identifying the main sources of the $\mathrm{CO}_{2}$ airlines individually generate, thereby allowing each airline to minimise emissions at the lowest cost to them.

Author Contributions: X.Y.: Conceptualisation, Methodology, Software, Formal analysis, Investigation, Writing-Original draft preparation, Project administration. J.B.: Conceptualisation, Methodology, Writing - Review and editing, Supervision, Project administration, Funding acquisition. All authors have read and agreed to the published version of the manuscript.

Funding: This work has emanated from research conducted with the financial support of Science Foundation Ireland (SFI) under the SFI Strategic Partnership Programme Grant Numbers SFI/15/SPP/E3125 and SFI/16/SPP/3347.

Institutional Review Board Statement: Not applicable.

Informed Consent Statement: Not applicable.

Data Availability Statement: Following the journals Guide for Authors, we wish to specify that the data that supports the findings of this study are openly available in the following URLs: Eurostat: https: / / ec.europa.eu/ eurostat/ data/ database (accessed on 29 June 2021), EUROCONTROL: https: / / ansperformance.eu/data / (accessed on 29 June 2021), OECD: https: / stats.oecd.org/ (accessed on 29 June 2021), U.S. EIA: https: / / www.eia.gov / (accessed on 29 June 2021). Otherwise, the data from CIRIUM require a subscription and are not publicly available. We cannot share the data that were collected from this database.

Conflicts of Interest: The authors declare no conflict of interest.

Appendix A. List of Air Routes in Europe

Table A1. The list of 150 air routes for 15 European countries.

\begin{tabular}{cccccccccc}
\hline ID & Route & ID & Route & ID & Route & ID & Route & ID & Route \\
\hline 1 & VIE-FRA & 31 & CPH-OSL & 61 & HEL-ARN & 91 & FCO-CTA & 121 & LIS-MAD \\
2 & VIE-ZRH & 32 & CPH-ARN & 62 & HEL-CPH & 92 & FCO-PMO & 122 & LIS-ORY \\
3 & VIE-CDG & 33 & CPH-LHR & 63 & HEL-LHR & 93 & FCO-CDG & 123 & LIS-LHR \\
4 & VIE-DUS & 34 & CPH-AMS & 64 & HEL-AMS & 94 & FCO-MAD & 124 & LIS-OPO \\
5 & VIE-TXL & 35 & CPH-CDG & 65 & HEL-FRA & 95 & FCO-LHR & 125 & LIS-BCN \\
6 & VIE-AMS & 36 & CPH-HEL & 66 & HEL-CDG & 96 & FCO-BCN & 126 & LIS-AMS \\
7 & VIE-HAM & 37 & CPH-FRA & 67 & HEL-MUC & 97 & FCO-AMS & 127 & LIS-CDG \\
8 & VIE-MUC & 38 & CPH-BRU & 68 & HEL-OSL & 98 & FCO-CAG & 128 & LIS-BRU \\
9 & VIE-FCO & 39 & CPH-ZRH & 69 & HEL-KUO & 99 & FCO-TRN & 129 & LIS-GVA \\
10 & VIE-CPH & 40 & CPH-MUC & 70 & HEL-AGP & 100 & FCO-FRA & 130 & LIS-MUC \\
11 & BRU-MAD & 41 & ATH-SKG & 71 & CDG-FCO & 101 & AMS-LHR & 131 & ARN-CPH \\
12 & BRU-BCN & 42 & ATH-HER & 72 & CDG-AMS & 102 & AMS-BCN & 132 & ARN-OSL \\
13 & BRU-LHR & 43 & ATH-CDG & 73 & CDG-BCN & 103 & AMS-CDG & 133 & ARN-HEL \\
14 & BRU-FCO & 44 & ATH-FCO & 74 & CDG-MAD & 104 & AMS-MAD & 134 & ARN-LLA \\
15 & BRU-LIS & 45 & ATH-RHO & 75 & CDG-FRA & 105 & AMS-FCO & 135 & ARN-LHR \\
16 & BRU-FRA & 46 & ATH-AMS & 76 & CDG-NCE & 106 & AMS-CPH & 136 & ARN-GOT \\
\hline
\end{tabular}


Table A1. Cont.

\begin{tabular}{cccccccccc}
\hline ID & Route & ID & Route & ID & Route & ID & Route & ID & Route \\
\hline 17 & BRU-GVA & 47 & ATH-FRA & 77 & CDG-MUC & 107 & AMS-LGW & 137 & ARN-AMS \\
18 & BRU-CPH & 48 & ATH-CHQ & 78 & CDG-TLS & 108 & AMS-MAN & 138 & ARN-MMX \\
19 & BRU-VIE & 49 & ATH-MUC & 79 & CDG-VIE & 109 & AMS-ZRH & 139 & ARN-UME \\
20 & BRU-AGP & 50 & ATH-ZRH & 80 & CDG-ZRH & 110 & AMS-FRA & 140 & ARN-FRA \\
21 & FRA-TXL & 51 & BCN-MAD & 81 & DUB-LHR & 111 & OSL-TRD & 141 & LHR-DUB \\
22 & FRA-LHR & 52 & BCN-PMI & 82 & DUB-LGW & 112 & OSL-BGO & 142 & LHR-AMS \\
23 & FRA-HAM & 53 & BCN-AMS & 83 & DUB-STN & 113 & OSL-SVG & 143 & LHR-FRA \\
24 & FRA-MUC & 54 & BCN-CDG & 84 & DUB-MAN & 114 & OSL-CPH & 144 & LHR-CDG \\
25 & FRA-VIE & 55 & MAD-LHR & 85 & DUB-BHX & 115 & OSL-ARN & 145 & LHR-EDI \\
26 & FRA-CDG & 56 & MAD-PMI & 86 & DUB-AMS & 116 & OSL-TOS & 146 & LHR-MAD \\
27 & FRA-MAD & 57 & MAD-ORY & 87 & DUB-CDG & 117 & OSL-LHR & 147 & LHR-MUC \\
28 & FRA-AMS & 58 & MAD-FCO & 88 & DUB-AGP & 118 & OSL-AMS & 148 & LHR-GLA \\
29 & TXL-ZRH & 59 & MAD-LIS & 89 & DUB-FRA & 119 & OSL-FRA & 149 & LHR-ZRH \\
30 & TXL-VIE & 60 & MAD-CDG & 90 & DUB-EDI & 120 & OSL-HEL & 150 & LHR-FCO \\
\hline
\end{tabular}

Note: Each route presents by ICAO airport code.

\section{Appendix B. Definitions of Research Variables}

Table A2. Definitions of variables.

\begin{tabular}{|c|c|c|}
\hline Variables & Notation & Definitions \\
\hline Number of departure passengers & Pax & $\begin{array}{l}\text { This parameter shows the total number of air passengers carried by the air transport } \\
\text { routes from the departure (origin) airport, broken down by country and month. }\end{array}$ \\
\hline Number of departure flights & Flights & $\begin{array}{l}\text { The parameter represents the total number of air passenger flights from the departure } \\
\text { airport on the air route. }\end{array}$ \\
\hline Average aircraft size & Asize & $\begin{array}{l}\text { The average aircraft size on the air transport route, calculated by dividing the passenger } \\
\text { seats available on the route by the number of air passenger flights on the route. }\end{array}$ \\
\hline Population of origin (departure) city & Population & $\begin{array}{l}\text { The total population of the origin city of the air route, broken down by country and year. } \\
\text { Here, we use the annual population to the monthly data, assuming that the population } \\
\text { of the city remains largely unchanged within the year. }\end{array}$ \\
\hline GDP per capita & GDPPC & An economic indicator to describe the economic conditions of the origin city. \\
\hline HICP by air transport & $\mathrm{HICP}$ & $\begin{array}{l}\text { HICP by air transport is the consumer price index of passenger transport by air, which as } \\
\text { a proxy measures the change over time of the prices of air passenger transport services } \\
\text { purchased by households in Europe, broken down by country and month. }\end{array}$ \\
\hline Herfindahl-Hirschman Index & HHI & $\begin{array}{l}\text { This parameter commonly used to account for the market concentration. In our study, } \\
\text { we use the ratio of the number of total seats provided by individual airlines to the } \\
\text { number of total seats of the route to calculate the market share (MS) of airlines on that } \\
\text { route. HHI is calculated as } H H I_{i t}=M S_{1 i t}^{2}+M S_{2 i t}^{2}+\ldots\end{array}$ \\
\hline Number of LCCs & LCCs & $\begin{array}{l}\text { The number of LCCs accounts for the number of Low-cost carriers provide service on } \\
\text { each route for each month. This information is hand collected from Cirium database and } \\
\text { it is a time-varying parameters. }\end{array}$ \\
\hline Jet fuel price & Jetfuel & $\begin{array}{l}\text { The jet fuel price is collected by the U.S. Gulf Coast Kerosene-Type Jet Fuel Spot Price } \\
\text { FOB, which is the monthly price in U.S. dollars per gallon. }\end{array}$ \\
\hline Distance & Distance & $\begin{array}{l}\text { This parameter measures the distance of each air route in kilometres, which is the } \\
\text { distance between airport pairs. }\end{array}$ \\
\hline International flights & International & $\begin{array}{l}\text { This information categorises the air route as either a domestic routes or an international } \\
\text { route. This variable is a dummy variable that takes the value one if the route is domestic } \\
\text { and zero otherwise. }\end{array}$ \\
\hline $\mathrm{CO}_{2}$ emission per route & $\mathrm{CO}_{2}$ & Total amount of $\mathrm{CO}_{2}$ emissions in ktonne of a particular route $i$ in month $t$. \\
\hline $\begin{array}{l}\text { Total available seat kilometres per } \\
\text { route }\end{array}$ & ASK & $\begin{array}{l}\text { This parameter measures the total available seat kilometres of each air route, it is } \\
\text { calculated as the total seats multiply by route distance. }\end{array}$ \\
\hline Total distance of total flights per route & KM & This parameter is calculated as the total number of flights multiply by the route distance. \\
\hline EU ETS included aviation & ETS & This information records when the aviation sector has been included the EU ETS. \\
\hline
\end{tabular}




\section{References}

1. EESI. Fact Sheet: The Growth in Greenhouse Gas Emissions from Commercial Aviation. 2019. Available online: https://www.eesi. org/papers/view / fact-sheet-the-growth-in-greenhouse-gas-emissions-from-commercial-aviation (accessed on 29 June 2021).

2. Gössling, S.; Humpe, A. The global scale, distribution and growth of aviation: Implications for climate change. Glob. Environ. Chang. 2020, 65, 102194. [CrossRef]

3. Chao, H.; Agusdinata, D.B.; DeLaurentis, D.; Stechel, E.B. Carbon offsetting and reduction scheme with sustainable aviation fuel options: Fleet-level carbon emissions impacts for U.S. airlines. Transp. Res. Part E Transp. Environ. 2019, 75, 42-56. [CrossRef]

4. Seufert, J.H.; Arjomandi, A.; Dakpo, K.H. Evaluating airline operational performance: A Luenberger-Hicks-Moorsteen productivity indicator. Transp. Res. Part E Logist. Transp. Rev. 2017, 104, 52-68. [CrossRef]

5. Anger, A.; Köhler, J. Including aviation emissions in the EU ETS: Much ado about nothing? A review. Transp. Policy 2010, 17, 38-46. [CrossRef]

6. Meleo, L.; Nava, C.R.; Pozzi, C. Aviation and the costs of the European Emission Trading Scheme: The case of Italy. Energy Policy 2016, 88, 138-147. [CrossRef]

7. ICAO. Online CORSIA Tutorial. 2016. Avaiable online: https://www.icao.int/environmental-protection/Pages/Online-CORSIATutorial.aspx (accessed on 29 June 2021).

8. Macintosh, A.; Wallace, L. International aviation emissions to 2025: Can emissions be stabilised without restricting demand? Energy Policy 2009, 37, 264-273. [CrossRef]

9. Brugnoli, A.; Button, K.; Martini, G.; Scotti, D. Economic factors affecting the registration of lower $\mathrm{CO}_{2}$ emitting aircraft in Europe. Transp. Res. Part E Transp. Environ. 2015, 38, 117-124. [CrossRef]

10. Schafer, A.W.; Evans, A.D.; Reynolds, T.G.; Dray, L. Costs of mitigating $\mathrm{CO}_{2}$ emissions from passenger aircraft. Nat. Clim. Chang. 2015, 6, 412-417. [CrossRef]

11. Muller, C.; Kieckhäfer, K.; Spengler, T.S. The influence of emission thresholds and retrofit options on airline fleet planning: An optimization approach. Energy Policy 2018, 112, 242-257. [CrossRef]

12. Chao, H.; Agusdinata, D.B.; DeLaurentis, D.A. The potential impacts of Emissions Trading Scheme and biofuel options to carbon emissions of U.S. airlines. Energy Policy 2019, 134, 110993. [CrossRef]

13. Yu, J.; Shao, C.; Xue, C.; Hu, H. China's aircraft-related $\mathrm{CO}_{2}$ emissions: Decomposition analysis, decoupling status, and future trends. Energy Policy 2020, 138, 111215. [CrossRef]

14. Kito, M.; Nagashima, F.; Kagawa, S.; Nansai, K. Drivers of $\mathrm{CO}_{2}$ emissions in international aviation: The case of Japan. Environ. Res. Lett. 2020, 15, 104036. [CrossRef]

15. Sharmina, M.; Edelenbosch, O.Y.; Wilson, C.; Freeman, R.; Gernaat, D.E.H.J.; Gilbert, P.; Larkin, A.; Littleton, E.W.; Traut, M.; van Vuuren, D.P.; et al. Decarbonising the critical sectors of aviation, shipping, road freight and industry to limit warming to $1.5-2{ }^{\circ} \mathrm{C}$. Clim. Policy 2020, 21, 455-474. [CrossRef]

16. Lo, P.L.; Martini, G.; Porta, F.; Scotti, D. The determinants of $\mathrm{CO}_{2}$ emissions of air transport passenger traffic: An analysis of Lombardy (Italy). Transp. Policy 2020, 91, 108-119. [CrossRef]

17. Sibdari, S.; Mohammadian, I.; Pyke, D.F. On the impact of jet fuel cost on airlines' capacity choice: Evidence from the U.S. domestic markets. Transp. Res. Part E Logist. Transp. Rev. 2018, 111, 1-17. [CrossRef]

18. Jorge-Calderón, J. A demand model for scheduled airline services on international European routes. J. Air Transp. Manag. 1997, 3, 23-35. [CrossRef]

19. Ito, H.; Lee, D. Assessing the impact of the September 11 terrorist attacks on U.S. airline demand. J. Econ. Bus. 2005, 57, 75-95. [CrossRef]

20. Pitfield, D.E.; Caves, R.E.; Quddus, M.A. Airline strategies for aircraft size and airline frequency with changing demand and competition: A simultaneous-equations approach for traffic on the north Atlantic. J. Air Transp. Manag. 2010, 16, 151-158. [CrossRef]

21. Pitfield, D.E.; Caves, R.E.; Quddus, M.A. A three-stage least squares approach to the analysis of airline strategies for aircraft size and airline frequency on the north Atlantic: An airline case study. Transp. Plan. Technol. 2012, 35, 191-200. [CrossRef]

22. Wadud, Z. Imperfect reversibility of air transport demand: Effects of air fare, fuel prices and price transmission. Transp. Res. Part A Policy Pract. 2015, 72, 16-26. [CrossRef]

23. Zhang, Y.; Wang, K.; Fu, X. Air transport services in regional Australia: Demand pattern, frequency choice and airport entry. Transp. Res. Part A Policy Pract. 2017, 103, 472-489. [CrossRef]

24. Miller, B.; Clarke, J.P. Strategic Guidance in the Development of New Aircraft Programs: A Practical Real Options Approach. IEEE Trans. Eng. Manag. 2008, 55, 566-578. [CrossRef]

25. Chin, A.T.; Tay, J.H. Developments in air transport: Implications on investment decisions, profitability and survival of Asian airlines. J. Air Transp. Manag. 2001, 7, 319-330. [CrossRef]

26. Ishutkina, M.; Hansman, R.J. Analysis of Interaction between Air Transportation and Economic Activity. In Proceedings of the 26th Congress of ICAS and 8th AIAA ATIO, Anchorage, AK, USA, 14-19 September 2008; p. 8888.

27. Marazzo, M.; Scherre, R.; Fernandes, E. Air transport demand and economic growth in Brazil: A time series analysis. Transp. Res. Part E Logist. Transp. Rev. 2010, 46, 261-269. [CrossRef]

28. Profillidis, V.; Botzoris, G. Air passenger transport and economic activity. J. Air Transp. Manag. 2015, 49, 23-27. [CrossRef] 
29. Hakim, M.M.; Merkert, R. Econometric evidence on the determinants of air transport in South Asian countries. Transp. Policy 2017, 83, 120-126. [CrossRef]

30. Abed, S.Y.; Ba-Fail, A.O.; Jasimuddin, S.M. An econometric analysis of international air travel demand in Saudi Arabia. J. Air Transp. Manag. 2001, 7, 143-148. [CrossRef]

31. Clewlow, R.R.; Sussman, J.M.; Balakrishnan, H. The impact of high-speed rail and low-cost carriers on European air passenger traffic. Transp. Policy 2014, 33, 136-143. [CrossRef]

32. Yap, G. The impacts of exchange rates on Australia's domestic and outbound travel markets. Math. Comput. Simul. 2013, 93, 139-150. [CrossRef]

33. Pacheco, R.R.; Fernandes, E. International air passenger traffic, trade openness and exchange rate in Brazil: A Granger causality test. Transp. Res. Part A Policy Pract. 2017, 101, 22-29. [CrossRef]

34. Gelhausen, M.C.; Berster, P.; Wilken, D. A new direct demand model of long-term forecasting air passengers and air transport movements at German airports. J. Air Transp. Manag. 2018, 71, 140-152. [CrossRef]

35. Chi, J. The impact of third-country exchange rate risk on international air travel flows: The case of Korean outbound tourism demand. Transp. Policy 2020, 89, 66-78. [CrossRef]

36. Wei, W.; Hansen, M. Impact of aircraft size and seat availability on airlines' demand and market share in duopoly markets. Transp. Res. Part E Logist. Transp. Rev. 2005, 41, 315-327. [CrossRef]

37. Wei, W.; Hansen, M. Airlines' competition in aircraft size and service frequency in duopoly markets. Transp. Res. Part E Logist. Transp. Rev. 2007, 43, 409-424. [CrossRef]

38. Boonekamp, T.; Zuidberg, J.; Burghouwt, G. Determinants of air travel demand: The role of low-cost carriers, ethnic links and aviation-dependent employment. Transp. Res. Part A Policy Pract. 2018, 112, 18-28. [CrossRef]

39. Wang, K.; Zhang, A.; Zhang, Y. Key determinants of airline pricing and air travel demand in China and India: Policy, ownership, and LCC competition. Transp. Policy 2018, 63, 80-89. [CrossRef]

40. Givoni, M.; Rietveld, P. Airline's choice of aircraft size-Explanations and implications. Transp. Res. Part A Policy Pract. 2009, 43, 500-510. [CrossRef]

41. Naumann, M.; Suhl, L. How does fuel price uncertainty affect strategic airline planning? Oper. Res. 2012, 13, 343-362. [CrossRef]

42. Bjelicic, B. Financing airlines in the wake of the financial markets crisis. J. Air Transp. Manag. 2012, 21, 10-16. [CrossRef]

43. Francis, G.; Humphreys, I.; Ison, S.; Aicken, M. Where next for low cost airlines? A spatial and temporal comparative study. J. Transp. Geogr. 2006, 14, 83-94. [CrossRef]

44. Pitfield, D. Ryanair's impact on airline market share from the London area airports: A time series analysis. J. Transp. Econ. Policy 2007, 41, 75-92.

45. Dobruszkes, F. New Europe, new low-cost air services. J. Transp. Geogr. 2009, 17, 423-432. [CrossRef]

46. Statistical office of the European Union. Database-Eurostat. Available online: https://ec.europa.eu/eurostat/web/main/data/ database (accessed on 29 June 2021).

47. EUROCONTROL. Data | Aviation Intelligence Unit Portal. Available online: https://ansperformance.eu/data/ (accessed on 29 June 2021).

48. OECD. OECD Statistics. Available online: https://stats.oecd.org/ (accessed on 29 June 2021).

49. Homepage-U.S. Energy Information Administration (EIA). Available online: https://www.eia.gov/index.php (accessed on 29 June 2021).

50. Robeco. Short-Haul Flights Are the Worst Offenders for $\mathrm{CO}_{2}, 2020$. Available online: https://www.robeco.com/en/insights/20 20/02/ short-haul-flights-are-the-worst-offenders-for-co2.html (accessed on 29 June 2021).

51. Valdes, V. Determinants of air travel demand in Middle Income Countries. J. Air Transp. Manag. 2015, 42, 75-84. [CrossRef]

52. Berry, S.; Jia, P. Tracing the woes: An empirical analysis of the airline industry. Am. Econ. J. Microecon. 2010, 2, 1-43. [CrossRef]

53. Hsiao, C.Y.; Hansen, M. A passenger demand model for air transportation in a hub-and-spoke network. Transp. Res. Part E Logist. Transp. Rev. 2011, 47, 1112-1125. [CrossRef]

54. Mumbower, S.; Garrow, L.A.; Higgins, M.J. Estimating flight-level price elasticities using online airline data: A first step toward integrating pricing, demand, and revenue optimization. Transp. Res. Part A Policy Pract. 2014, 66, 196-212. [CrossRef]

55. Graver, B.; Rutherford, D.; Zheng, S. $\mathrm{CO}_{2}$ Emissions From Commercial Aviation: 2013, 2018, and 2019. 2020; pp. 1-36. Available online: https:/ / theicct.org/publications/co2-emissions-commercial-aviation-2020 (accessed on 29 June 2021).

56. Peeters, P.; Rietveld, P.; Schipper, Y. Deregulation in European aviation and the evolution of hub-and-spoke networks: Impacts on the environment. In Regions, Land Consumption and Sustainable Growth: Assessing the Impact of the Public and Private Sectors; Edward Elgar Publishing: Northampton, MA, USA, 2005; pp. 137-153. 